\title{
Cloud Based Working and Teaching System in Higher Education A Case Study of Teaching Computer Networking
}

\author{
Yongbin Zhang ${ }^{1, \text { a }}$, Ronghua Liang ${ }^{2, \mathrm{~b}}$, Shulin Yang ${ }^{3, \mathrm{c}}$ \\ ${ }^{1}$ China Industrial Economic Security Research Center, Beijing, 100044, China \\ ${ }^{2}$ Department of Teaching Technology and Network Information, Beijing Institute of Graphic \\ Communication, 102600, China \\ ${ }^{3}$ Department of Information Engineering, Beijing Institute of Graphic Communication, 102600, \\ China
}

aemail: zhangyongbin@bigc.edu.cn bemail:liangronghua@bigc.edu.cn cemail:dzyshul@bigc.edu.cn

Keywords: cloud computing; teaching system; higher education; Infrastructure as a Service

\begin{abstract}
Information and network technologies have been widely used in education, especially in higher education. With the prevailed use of computer at office, in classroom and at home, teachers have to deal with different computer environments, which bring teachers many big challenges, such as how to manage version control of the same work and how to make sure availability of the same software in differential working environments. To solve the problems coming with different working environment, we presented a cloud based working and teaching system for teachers in higher education. With this model, each teacher will work and teach with the same computer environment from wherever at any time as long as internet connection is available. Working and teaching with this cloud based system, teachers can focus on their work. There is no need to worry about underline computer infrastructure, such as storage and security. With a single working and teaching computer environment, a teacher does not worry about problems such as version control and software compatibility. We demonstrated method to use this model when we taught computer networking course for undergraduate students.
\end{abstract}

\section{Introduction}

The increased use of technology for improved teaching and enhanced learning is going to be the future of education at all levels[1].More and more universities have been using computer and network to help teaching and learning[2]. Computers, mobile devices and the internet are standard aspects of daily practices. Email is the main communicative channel in working contexts. Google is the first port for searching information. Word and Powerpoint are standard tools for production of content[3]. Computer and network have become necessary part of university teachers' academic and teaching career. A teacher may prepare his or her lectures on the computer at home and continue the work at office. Then he or she may give lecture with the computer in classroom.

The increased use of computer helps teachers to work and teach more effectively. But at the same time, it also brings some challenges. For example, it is difficulty for a teacher to keep the synchronization of the same work on different computer environments. The version compatibility of software installed on different computer environments is another problem needed to be solved.

It is a big challenge for universities to help teachers access the same document or the same software at different locations efficiently. When giving a lecture, a teacher might find that his or her carefully prepared document couldn't be opened with the office suite installed on the computer in classroom.

More and more efforts focus on how to make teaching and learning more effective and efficient. Some system is modeled to make sure that students working with the learning system have the same feeling as face to face learning[4]. Some systems provide a virtual learning environment[5]. With virtual learning platform, students can learn their courses according to their time and interest. Teachers provide all the courses material and upload the material to the virtual learning system. 
All these teaching and learning models help teachers to manage and organize their course material and help students to learning. But teachers in higher education still face problems such as version control of their working content and application software availability when teachers work on different computers in different locations.

In this paper, a cloud-based working and teaching system for teachers in higher education is presented to solve the problems mentioned above with Infrastructure as a Service (IaaS) model. A teacher can apply for a virtual machine with working and teaching requirement with web browser. The cloud management system will automatically allocate resource for requester. There is no need for teachers to manage their personal computer. Teachers can access the platform from anywhere as long as internet connection is available. Teachers can work and prepare their lecture at home or at office. Teachers access the same content wherever and whenever they are without worrying about content synchronization and different versions of software used. With the model, teachers in higher education will have a single working and teaching environment. This will save teachers much time and effort by eliminating the changing among different working and teaching environments and teachers can focus on their work.

\section{TEACHING AND LEARNING SYSTEMS}

There are many learning and teaching systems existed at present. Blackboard[6] is one of the most popular ones. Blackboard is a comprehensive online learning platform. Students can access the platform with various devices, such as personal computer, tablet and mobile phone. Moodle is another popular learning management system[7]. Moodle can be used to conduct full on line courses. As an open source e-learning platform, Moodle is in continual active evolution. More and more new features are added into Moodle. Students and teachers can access Moodle with Mobile phone or tablet.

Besides these learning platforms provided by companies, some researchers also presented different teaching and learning systems. In 2010 Mohanmmed Al zoube and Samir Abou El-Seoud presented the architecture of a web e-learning system[1]. The system had three major functions including the web-based course management system, personal learning environment with IGoogle as a portal and smart agents. IGoogle and gadgets were used as platform for learner in the system. This is a cloud based e-learning system. Users of the system can access the system with different devices as long as internet connection is available.

The applications and studies above provide useful ways for teachers to share teaching material and provide an interactive learning environment. Most teaching and learning platforms need teachers to upload teaching material and other related resources. But there is not much research cover the problem that how to help teachers prepare teaching work more conveniently.

Google Apps for Education[8] is one of the most useful free cloud computing applications. Google Apps for Education includes Gmail for email and Google Docs for documents, spreadsheets, and presentations. With these cloud applications, everybody can work on the same document at the same time in a collaborative manner. But the problem is that some Google Apps for Education are not available for teachers in China.

\section{PROBLEMS AND CHALLENGES IN BIGC}

At present, teachers in Beijing Institute of Graphic Communication (BIGC) can prepare their teaching task with their own computer at the offices. Each classroom has been equipped with computer in every classroom and internet connection is available. BIGC also provides E-mail services for students and teachers. There is no uniform teaching and learning platform. Some teachers have built their own personal teaching platform, which is a web application, with help of IT department. With personal teaching platform, teacher can upload related course and teaching material to the web site and students enrolled can download the material. While most of other teachers who haven't built the web applications bring teaching material, such as documents and presentation slides to classes and copy the material to the computer in the classroom. 
Those who had web application as teaching and learning platform have the advantage over teachers hadn't ones. First, as a web application owner, the teacher can upload teaching content and related resource into the teaching and learning platform without keeping a copy of teaching resource with flash disk or other storage. At the same time, students enrolled can download the resource from web site from anywhere.

Teachers who haven't built a personal learning web application have to use other methods. Many of them use email as the main method to save and keep their work. Others use external storage, such as flash disk, or movable hard disk. Because the different computer environments exist, teachers have to deal with different problems, such as the compatibility problem of application software version, and synchronization problem of their working content. For example, some teachers cannot open their document in classroom just because the version of the office software install on the PC in the classroom is lower than the one installed on the PC at home or office. Some teachers find that software needed is not installed on the PC in classroom. All these facts bring teachers many difficulties in teaching.

Some teachers also bring their own laptop into classroom. With their own computer, teachers can do their work at their will. It is the fact that not all teachers have laptop. Even for those who have laptop, they have to face the problem that it is hard for teachers to keep the laptop with them all the time. Sometime it is hard to make sure their laptop work well all the time. Some teachers find that they have difficulties to keep their laptops work with the devices in classroom.

Most teachers face some common problems and challenges while they are working and teaching in Beijing Institute of Graphic Communication. At first, if a teacher needs software which is not installed on the computer in the classroom, the teacher has to install the software by himself. Because the computer in classroom boots from network, the computer is turned to initial status every time the computer restarts. That means the teacher has to install the same software for each lecture or the teacher can ask the IT department to install the software and change the initial status of network booting. It is impossible for IT department to install all the software needed by all the teachers. At present, if a teacher needs software, he or she has to install the software every time.

Secondly, because teachers have to work with at least three different computer environments, at home, at office and in classroom, this brings a few challenges for teachers. The version control of teachers' working tasks is a big challenge. Teacher without teaching and learning platform, they have to keep different versions of their tasks. Maybe a teacher starts his task at home, continues his work at office, and then he may use the material in classroom. The teacher has to keep a copy of his current work with him. So how to deal with different versions of the same work is a big problem and it cost many efforts and much time. Even with the teaching and learning platforms, teachers have to deal with version control problem. The teaching and learning platform works as a network storage so teacher just upload his material to the platform instead of using email or movable hard disk.

Another challenge is problem of different versions of application software. For example, if a teacher use Microsoft office 2010 at home, he may not open the document if Microsoft office 2003 is installed on the computer in classrooms unless he has to convert his working documents to the correct version. That is a tedious task for teachers.

\section{CLOUD BASED TEACHING PLATFORM}

At present, most famous teaching and learning platforms is web based. From the information we know, almost all could-based teaching and learning platform are provided using Software as a Service model (SaaS). With Saas model, it is very convenient for teachers and students access this kind of platform with web browser as shown in Figure. 1. With SaaS model, teachers don't need to maintain the platform. The potential problem is that if a teacher needs special software for academic or teaching work, SaaS cloud service provider usually can’t meet the requirement. 


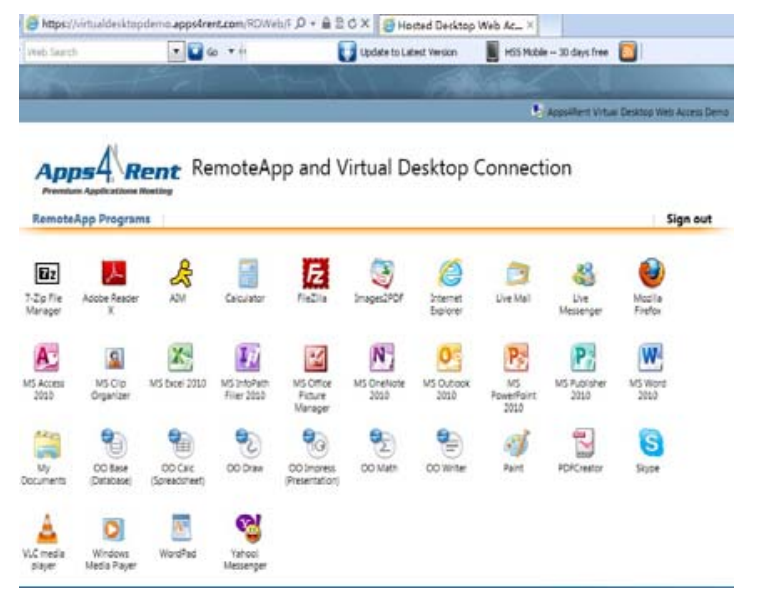

Fig.1. Different applications with SaaS model

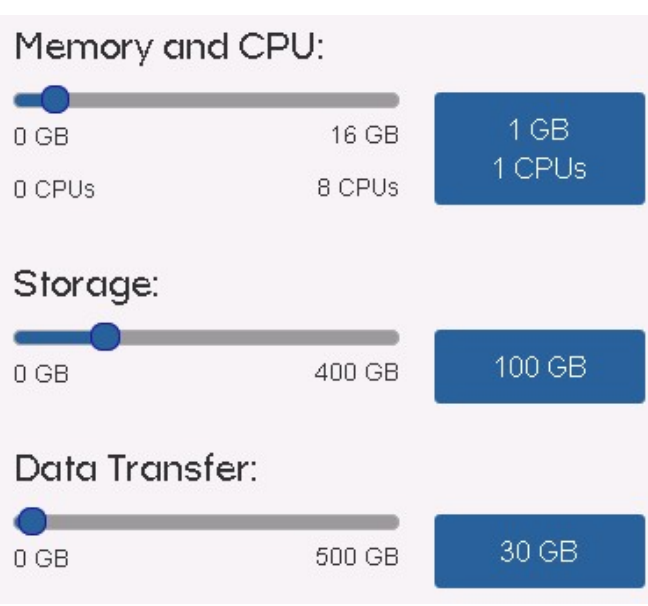

Fig.2. Computing resource

We presented a working and teaching system with an Infrastructure as a Service (IaaS) model to provide teachers the same working and teaching platform to solve the problems mentioned above. With Iaas service model, computing resources such as hard disk, network, memory, and CPU are pooled. Any teacher can apply for a virtual instance on-demand from Infrastructure as a Service (IaaS) provider. IaaS Service provider then creates an instance for the applier according to their requirements automatically. The service provider will be responsible for the operating system, security software and other commonly used applications such as word processing and sheet applications. With IaaS service, a teacher can access his or her own computing system from anywhere and anytime as long as internet connection is available. For example, if a teaching is working at home in the morning with word processing application, then he leaves for university, he can continue to work on the same document even without reopen it at university.

\section{CASE STUDY IN TEACHING COMPUTER NETWORKING}

We have been teaching computer networking for non-computer majors since 2009 in Beijing Institute of Graphic Communication. There is a web based teaching and learning platform, which we can upload our teaching material to and students can download the material from. We use Office applications and network simulator tool named Packet Tracer provided by Cisco Networking Academy [10] in working and teaching. We usually prepared our teaching work at home or at office, then we uploaded related documents to our web server so that we could continue our work and access the documents in different locations. So there were many different versions of the same work content at home and at office. It took us much time to make sure that we got the latest updated content. Because computers in classroom are booted from network, the computers restore to initial state after rebooting. When we were giving lecturing in classroom, we had to install the network simulator tool each time.

To build an Infrastructure as a Service as a working and teaching platform, we have many choices. We can built a private cloud prototype with open source cloud operating system such as OpenStack[11] and with Kernel Based Virtual Machine (KVM)[12] virtualization technology. Or we can just use the IaaS services provided by other companies.

We chose to use services provided by other companies to make things simple because there isn't enough finical support at present.

Teachers authorized can apply for an instance with specified requirement, including CPU, memory and hard disk, using web browser as shown in Figure. 2.

With this working and teaching platform, we had one single computing environment. We could prepare our work at home or at office. When we gave lectures in classroom, we just worked on the same computing environment without worrying about version control and software reinstall problems any more. 


\section{CONCLUSION AND DISCUSSION}

With Infrastructure as a Serviced cloud service model, teachers can access the system from anywhere at any time as long as internet connection is available. Because there is only one working and teaching environment, teachers don't need to care about the synchronization of their working artifact. At present, our just used the service provide by other company. In the future, we will research on how to build our own Infrastructure as a Service system with open source software and deepen our understanding about cloud computing theory and technologies.

\section{ACKNOWLEDGMENT}

In this paper, the research was sponsored by Beijing Municipal Commission of Education (Project No. KM201310015008), the Importation and Development of High-Caliber Talents Project of Beijing Municipal Institutions and Beijing Institute of Graphic Communication (Project No. E-a-2012-28).

\section{REFERENCES}

[1] Mohammed Al-Zoube and Samir Abou El-Seoud, Cloud Computing Based E-Learning System, International Journal of Distance Education Technologies,vol. 8 ,pp. 58-71, 2012.

[2] H. c. R. Ponce, Instructional effectiveness of a computer-supported program for teaching reading comprehension strategies, Computers and Education, vol.59, pp. 1170-1183,2012

[3] Grainne Conole and Juliette Culver, The design of Cloudworks: Applying social networking practice to foster the exchange of learning and teaching ideas and designs, Computers \& Education, 54 ,pp.679- 692, 2010.

[4] shu-hai Zhou, Building and practicing of interactive three-dimensional teaching network resources platform based on cloud technology, International Journal of Advancements in Computing Technology,vol. 4, pp. 444-451, 2012.

[5] E. Gutiérrez De Ravé, A computer application for teaching and learning approximation and interpolation algorithms of curves, Computer Applications in Engineering Education, vol.19,pp.40-47, , 2011 .

[6] Blackboard. http://www.blackboard.com/Platforms/Learn/Overview.aspx .( last accessed 2013)

[7] Moodle platform. https://moodle.org/ . (last accessed 2013)

[8] Google Apps for education. www.google.com/apps/education . (last accessed 2013) .

[9] The NIST Definition of Cloud Computing. http://csrc.nist.gov/publications/PubsSPs.html\#800-145, 2011.

[10]Cisco Network Academy. https://www.netacad.com/ (last accessed 2013).

[11] Openstack Compute. http://www.openstack.org/software/openstack-compute/ . (last accessed 2013).

[12] Kernel Based Virtual Machine. http://www.linux-kvm.org/page/Main_Page . (last accessed 2013) 